\title{
Gene-by-Environment (Serotonin Transporter and Childhood Maltreatment) Interaction for Anxiety Sensitivity, an Intermediate Phenotype for Anxiety Disorders
}

\author{
Murray B Stein*,', Nicholas J Schork ${ }^{2}$ and Joel Gelernter ${ }^{3}$ \\ 'Anxiety and Traumatic Stress Disorders Program, Departments of Psychiatry and Family \& Preventive Medicine, University of California San \\ Diego, La Jolla, CA, USA; ${ }^{2}$ Genetic Polymorphism Laboratory, Departments of Psychiatry, Family \& Preventive Medicine, and Biostatistics, \\ University of California San Diego, La Jolla, CA, USA; ${ }^{3}$ Departments of Psychiatry, Genetics, and Neurobiology, Yale University School of Medicine, \\ New Haven, CT, USA
}

Anxiety sensitivity (AS) is a dispositional characteristic that predisposes to the development of anxiety disorders (eg, panic and posttraumatic stress disorder) and major depression. AS is subject to genetic and environmental influences, the former as yet unidentified and the latter known to include childhood maltreatment. The serotonin transporter gene (SLC6A4) promoter polymorphism (5-HTTLPR) has been associated with depression, but most consistently in the context of environmental stress. We tested the hypothesis that 5-HTTLPR genotype and childhood maltreatment would interact to increase susceptibility to AS in young adults. Subjects were European-American college undergraduates ( $N=150$, median age 18 years) characterized on a measures of AS (Anxiety Sensitivity Index) and retrospective childhood maltreatment (Childhood Trauma Questionnaire [CTQ]). 5-HTTLPR genotypes were obtained from blood-derived DNA. Linear regression was used to model relationships between 5-HTTLPR, childhood emotional abuse, and AS; covariates such as sex, neuroticism, and ancestral proportion scores were incorporated into some models in a larger, ethnically heterogenous sample $(\mathrm{N}=247)$ to evaluate robustness of the findings to model assumptions. A statistically signficant interaction was observed between levels of childhood emotional (or physical) maltreatment and 5-HTTLPR genotype. Specifically, S/S individuals with higher levels of maltreatment had significantly higher levels of AS than subjects in other groups. No such relationship was found for neuroticism, attesting to the possible specificity of the findings for AS. Findings were consistently robust to the inclusion of covariates, and were not confounded by population stratification. In conclusion, these results provide evidence of a specific genetic influence on anxiety sensitivity - an intermediate phenotype for anxiety (and depressive) disorders; this effect is modified by severity of childhood maltreatment. These findings are consistent with the notion that 5-HTTLPR operates broadly to moderate emotional responsivity to stress.

Neuropsychopharmacology (2008) 33, 312-319; doi:I0.1038/sj.npp. I30I422; published online 25 April 2007

Keywords: anxiety; anxiety sensitivity; 5-HTTLPR; child abuse; emotional abuse; gene-environment interaction

\section{INTRODUCTION}

Anxiety sensitivity (AS) refers to the fear of anxiety-related sensations. AS is characterized by the belief that these sensations have harmful consequences (Reiss, 1991). For example, an individual may fear that the sensation of palpitations is indicative of a serious, life-threatening condition, such as a 'heart attack.' Some individuals are more prone than others to respond to anxiety symptoms in this fashion; the higher an individual's level of AS, the more that individual is likely to experience anxiety symptoms as alarming, dangerous, and threatening. The phenotypic

*Correspondence: Dr MB Stein, Anxiety and Traumatic Stress Disorders Program, Departments of Psychiatry and Family \& Preventive Medicine, University of California San Diego, La Jolla, CA 92093-0855, USA, Tel: + | 858534 645 |; Fax: + | 858534 6460,

E-mail: mstein@ucsd.edu

Received 19 December 2006; revised 8 March 2007; accepted 9 March 2007 structure of AS is stable across diverse samples (Bernstein et al, 2006), attesting to the generalizability of this construct.

AS is a well-established risk factor for the development of panic attacks. In a series of prospective studies of healthy young adults under stress (eg, basic military trainees), AS was found to predict the subsequent onset of panic attacks (as well as generalized anxiety and depressive symptoms) (Schmidt et al, 1997, 1999). Similar findings were obtained in a prospective study of healthy adolescents (Hayward et al, 2000). AS also predicts fearful responding to a number of biological challenge procedures (Stein and Rapee, 1998), notably carbon dioxide $\left(\mathrm{CO}_{2}\right)$ inhalation (Schmidt and Mallott, 2006), the anxious response which has also been noted to be moderately heritable (Battaglia et al, 2007). The role of AS may be most pronounced in panic disorder, but scores on the Anxiety Sensitivity Index (ASI) (Peterson and Reiss, 1992), the most frequently used measure of AS, are also elevated in other anxiety disorders, such as 
post-traumatic stress disorder (PTSD) (Bernstein et al, 2005; Lang et al, 2002). Furthermore, AS has also been associated with the severity of depressed mood (Cox et al, 1999b; Taylor et al, 1996; Zinbarg et al, 2001) suggesting that its influence may extend beyond the anxiety disorders to other Axis I forms of psychopathology (Schmidt et al, 2006).

Individual differences in AS are thought to arise from the combined influences of experiential and genetic factors. Twin research has shown that variation in AS (particularly the physical concerns aspect of AS) is explained by unique (as opposed to shared) environmental and additive genetic influences (Stein et al, 1999). Emotional maltreatment in childhood - particularly when it includes parental threatening, hostile, and rejecting behaviors - is associated with higher levels of AS in young adults (Scher and Stein, 2003). Thus, childhood emotional maltreatment is a plausible candidate to be an environmental risk factor for AS.

No specific genetic vulnerability factors for AS have yet been identified, but a strong candidate emerges from a convergence of findings with a functional length polymorphism in the promoter of the serotonin transporter gene (gene, SLC6A4; variant, 5-HTTLPR). This polymorphism has functional importance in that the 'short' (S) variant is less transcriptionally efficient than the 'long' (L) variant (Lesch et al, 1996). The 5-HTTLPR polymorphism has been shown in many (Caspi et al, 2003; Eley et al, 2004; Grabe et al, 2005; Jacobs et al, 2006; Kaufman et al, 2004, 2006b; Kendler et al, 2005; Wilhelm et al, 2006; Zalsman et al, 2006), but not all (Gillespie et al, 2005; Surtees et al, 2006) studies to interact with stressful life events to increase susceptibility to major depression or depressive symptoms. In one of these recent studies, the investigators surmised that this genotype-by-environment interaction might be best understood as involving mechanisms more proximal to psychological experience (eg, negative affectivity) than to a direct risk pathway to psychiatric illness (Jacobs et al, 2006). Following this line of reasoning, we hypothesized that a similar relationship would explain some of the interindividual variation in AS, which is itself a risk factor for anxiety and depressive disorders. This expectation was further bolstered by the finding of a gene (again, SLC6A4 variant 5-HTTLPR)-by-environment (social support) interaction in the prediction of another anxiety-related trait-behavioral inhibition with unfamiliar peers in childhood (Fox et al, 2005), which is a risk factor for anxiety disorders such as social phobia (Biederman et al, 2001).

We therefore designed this study to test the hypothesis that self-reported emotional maltreatment in childhood would moderate the effects of 5-HTTLPR genotype on AS scores in young adults. Given preliminary evidence that it is the physical concerns component of AS that is heritable (Stein et al, 1999), we looked at this component in addition to overall AS scores. We chose to focus on emotional maltreatment (as opposed to other available indices of childhood maltreatment, such as sexual abuse) primarily for epidemiological reasons: it is not a rare event, and it has good variability in population-based samples (Scher et al, 2004; Thombs et al, 2006). But we also looked at physical abuse to test for specificity of the effect.

In light of the finding that an a/g single-nucleotide polymorphism (SNP; rs25531) in the variable region that defines the variable number of tandem repeats (VNTR) S/L polymorphism divides $L$ alleles of 5-HTTLPR into two functionally different variants, $\mathrm{La}$ and $\mathrm{Lg}$ ( $\mathrm{Hu}$ et al, 2005; Wendland et al, 2006), the latter of which has been reported to behave equivalently to the $S$ allele in terms of its low transcriptional efficiency, we also genotyped subjects for this SNP polymorphism and repeated analyses with this tetra-allelic (the SNP variant also occurs, rarely, on the $S$ allele) reclassification. We also repeated analyses using the rs25531 SNP alone.

\section{METHODS}

\section{Sample and Procedures}

Participants $(N=247)$ were 171 women and 76 men (mean age 18.8 years, SD 1.5 years) recruited from among undergraduate psychology students at San Diego State University (SDSU) who had, in a group testing session (at which some questionnaires were completed and demographic information provided), indicated their willingness to be contacted by research investigators to participate in future psychological experiments. A subset of subjects $(N=150)$ was identified, consisting of all those who described themselves as being of European-American (Caucasian) ancestry; initial analyses were conducted on this subset in order to reduce the possibility of confounding by population stratification (Freedman et al, 2004).

Subjects each came for a scheduled appointment at which a blood sample $(60 \mathrm{ml})$ was drawn for genetic studies and the subjects completed questionnaires and/or computerized tasks. Subjects gave informed, written consent to participate in this part of the study, which was approved by the Human Research Protection Programs at both SDSU and the University of California, San Diego. Subjects received \$25 for providing the blood sample.

\section{Questionnaires}

Psychiatric diagnostic interviews were not available for all subjects. All subjects completed a panel of self-report measures relevant to the study of personality and anxietyrelated traits. Those measures that were examined for the purposes of this report are:

Anxiety Sensitivity Index (ASI). A 16-item self-report measure of anxiety sensitivity ('fear of fear') (Peterson and Reiss, 1992); scores range from 0 to 64 . The ASI has three factors that deal with physical (eg, 'It scares me when my heart beats rapidly'), psychological (eg, 'It scares me when I am unable to keep my mind on a task') and social (eg, 'Other people notice when I feel shaky') consequences of anxiety symptoms, respectively.

NEO personality inventory-revised (NEO-FFI). A widely used, 60-item self-report measure of personality, grouped into five major domains: neuroticism, extraversion, openness to experience, conscientiousness, and agreeableness (Costa and McCrae, 1992). T scores were calculated directly from college-age, sex-specific norms (Robert R McCrae $\mathrm{PhD}$, personal communication, November 14, 2001). Neuroticism (as defined through the NEO) is a well- 
established, nonspecific risk factor for anxiety and mood disorders (Middeldorp et al, 2005). Given the partial conceptual overlap between AS and N (Cox et al, 1999a; Smoller and Tsuang 1998; Zinbarg et al, 2001), we included neuroticism as a covariate in some models in order to isolate genetic effects more specific to AS.

Childhood trauma questionnaire (CTQ). A 28-item retrospective self-report questionnaire designed to assess five types of negative childhood experiences (Bernstein et al, 1994; Scher et al, 2001). Given the study hypotheses, and in an effort to minimize multiple comparisons, we focused on the Emotional Abuse (EA) component of this instrument. But, in order to evaluate specificity for EA, we also ran a parallel series of analyses with the Physical Abuse (PA) component of the CTQ.

Questionnaire scores for subjects in the three genotypic groups are shown in Table 1.

\section{Genotype Analysis}

Genomic DNA was extracted from whole blood and the 5HTTLPR variant was analyzed by polymerase chain reaction (PCR) amplification, as described elsewhere for the diallelic L-S classification (Gelernter et al, 1997), and for the tetraallelic La/Lg-Sa/Sg classification (Stein et al, 2006). Within the ethnically homogenous European-American sample $(N=150)$, distribution of 5-HTTLPR alleles for to the diallelic classification was L $57 \%$ and S $43 \%$; there was no significant deviation from HWE expectations $\left(\chi^{2}=0.81\right.$, $\mathrm{df}=1, p=0.37)$. For the triallelic system, the distribution of

Table I Characteristics of Study Participants by 5 -HTTLPR Diallelic Genotype ( $N=247)$

\begin{tabular}{|c|c|c|c|c|c|}
\hline Variable & Obs & Mean & Std. dev. & Min & Max \\
\hline \multicolumn{6}{|l|}{$5-H T T L P R=L / L$} \\
\hline Age (years) & 71 & 18.58 & 1.06 & 18 & 24 \\
\hline ASI total & 71 & 19.80 & $|1.6|$ & 3 & 62 \\
\hline NEO-N & 71 & 47.30 & 10.78 & 25 & 78 \\
\hline CTQ-EA & 71 & 8.18 & 3.95 & 5 & 25 \\
\hline CTQ-PA & 71 & 6.11 & 2.88 & 5 & 22 \\
\hline \multicolumn{6}{|l|}{$5-H T T L P R=L / S$} \\
\hline Age (years) & 108 & 18.82 & 1.82 & 18 & 31 \\
\hline ASI total & 108 & 17.36 & 9.52 & । & 47 \\
\hline NEO-N & 108 & 47.97 & 9.98 & 24 & 75 \\
\hline CTQ-EA & 108 & 8.27 & 4.09 & 5 & 24 \\
\hline CTQ-PA & 108 & 6.71 & 3.29 & 5 & 24 \\
\hline \multicolumn{6}{|l|}{$5-H T T L P R=S / S$} \\
\hline Age (years) & 68 & 18.89 & 1.11 & 18 & 22 \\
\hline ASI total & 68 & 21.32 & 11.95 & 3 & 50 \\
\hline NEO-N & 68 & 48.62 & 9.87 & 22 & 77 \\
\hline CTQ-EA & 68 & 8.62 & 4.01 & 5 & 25 \\
\hline CTQ-PA & 68 & 7.69 & 3.54 & 5 & 24 \\
\hline
\end{tabular}

Neuropsychopharmacology alleles was La 51\%, Lg 6\%, and S $43 \%$ with no significant deviation from $\mathrm{HWE}$ expectations $\left(\chi^{2}=1.87, \mathrm{df}=3\right.$, $p=0.60$ ).

\section{Ancestral Proportion Scores}

Subjects' ancestries were estimated using a set of unlinked genetic markers by Bayesian cluster analysis, using the procedures and software developed by Pritchard and colleagues (http://pritch.bsd.uchicago.edu/software.html) (Falush et al, 2003; Pritchard et al, 2000; Pritchard and Rosenberg, 1999). Pritchard's software program STRUCTURE implements Bayesian cluster modeling that can recognize cryptic population genetic patterns without prior information of population origins. Data were submitted to the program STRUCTURE using 35 markers with models specified as 'admixture' and 'allele frequencies correlated' and 500000 burn-in and 500000 MCMC (Markov Chain Monte Carlo) iterations. The markers were the set of STRs described previously (Yang et al, 2005). A two-cluster solution classified 149 of the 150 European American subjects in complete concordance with their reported ethnicity.

\section{Statistical Analysis}

Analyses were conducted using the biostatistical analysis program STATA (Version 9.2) (StataCorp, 2003). The tetraallelic or, in the case of this sample, triallelic genotypes - we found no instances of Sg alleles - were reclassified into a biallelic model by their level of expression as follows: $\mathrm{Lg} / \mathrm{S}$, $\mathrm{Lg} / \mathrm{Lg}$, and $\mathrm{S} / \mathrm{S}$ were reclassified as $\mathrm{S}^{\prime} \mathrm{S}^{\prime}, \mathrm{La} / \mathrm{S}$ and $\mathrm{La} / \mathrm{Lg}$ were reclassified as $\mathrm{L}^{\prime} \mathrm{S}^{\prime}$, and $\mathrm{La} / \mathrm{La}$ was reclassified as $\mathrm{L}^{\prime} \mathrm{L}^{\prime}$ (Parsey et al, 2006).

Linear regression techniques in STATA ('rreg') (StataCorp, 2003) that are considered robust to outliers were used to model the relationships between 5-HTTLPR genotype (coded as 0 for LL or $L^{\prime} L^{\prime}, 1$ for LS or $L^{\prime} S^{\prime}$, and 2 for SS or $S^{\prime} S^{\prime}$ ), level of emotional abuse (CTQ-EA), and AS (Basic Model); additional covariates included in some models were sex (Model 1); and sex and ancestral propotion scores (Model 2). (Models were rerun with the AS-Physical Concerns subscale (rather than total AS score) as the outcome.) A third model added neuroticism as a covariate with the aim of isolating effects of AS that are not attributable to shared variance with neuroticism (Model 3). Models 1 and 2 were also applied to neuroticism rather than AS to determine specificity of effects for AS. Analagously, Models 1 and 2 were run with physical abuse (CTQ-PA) rather than emotional abuse (CTQ-EA) to determine specificity of the $G \times E$ interaction for the latter. Multivariate regression analyses were run in the full sample $(N=247)$ to take advantage of this larger, more diverse sample, but were also rerun constrained to the EuropeanAmerican sample $(N=150)$; in light of recent findings that there may be stratification even among self-identified European-American samples (Campbell et al, 2005), these analyses also included the ancestral proportion scores as covariates (Models 2 and 3).

An additional set of analyses, as described above, was conducted using rs 25531 to classify individuals $(N=237$ subjects: $a \mathrm{a}=209, \mathrm{ag}=25, \mathrm{gg}=3$ ). There were no signifi- 
cant main effects found for rs25531 and no significant interactions with the childhood maltreatment variables. These data are not shown, but are available upon request from the corresponding author.

\section{RESULTS}

\section{Overall AS Levels in European-American Subjects $(N=150)$}

There were no significant main effects of 5-HTTLPR genotype (either diallelic or triallelic) on emotional abuse scores (CTQ-EA) in regression models that incorporated sex and the ancestral proportion scores as covariates.

The relationships between the variables of interest were first modeled (Basic Model) as a main effect of level of emotional abuse (CTQ-EA) $(\beta=0.30$ (SE $\beta=0.40), t=0.75$, $p=0.46)$, 5-HTTLPR genotype $(\beta=-5.18$ (SE $\beta=2.79)$, $t=-1.86, p=0.065)$, and the interaction of these two factors $(\beta=0.64$ [SE $\beta=0.32], t=2.02, p=0.045)$. To discern the nature of this statistically significant interaction, we stratified by 5-HTTLPR genotype and compared the main effects of emotional abuse level across genotypes (Figure 1): L/L $(\beta=0.881, \quad \mathrm{SE} \beta=0.515, \quad N=52) ; \mathrm{L} / \mathrm{S}$ $(\beta=0.634, \quad$ SE $\beta=0.240, \quad N=68) ; \quad$ S $/ \mathrm{S} \quad(\beta=1.743, \quad$ SE $\beta=0.407, N=30)$. S/S homozygotes had significantly greater slopes than S/L heterozygotes $(t=2.46, \mathrm{df}=96$, $p=0.016)$ but not $\mathrm{L} / \mathrm{L}$ homozygotes $(t=1.16, \mathrm{df}=80$, $p=0.251)$. We therefore also contrasted S/S homozygous genotypes $v s \mathrm{~L} / \mathrm{L}$ or $\mathrm{L} / \mathrm{S}$ genotypes grouped together ( $\beta=0.665$, SE $\beta=0.228$ ) and found that the slopes of the latter were also statistically significantly greater $(t=2.18$, $\mathrm{df}=148, p=0.03)$. This difference in slopes reflects the interaction between genotype and childhood maltreatment such that at the upper end of the emotional abuse range, S/S homozygotes had higher AS scores than other subjects.
Very similar results (Basic Model) were obtained for the triallelic 5-HTTLPR classification (interaction term: $\beta=0.530$ (SE $\beta$ 0.309), $t=1.72, p=0.088$ ), although the comparison of the beta weights of $\mathrm{La} / \mathrm{La}, \mathrm{La} / \mathrm{Lg}$, or $\mathrm{La} / \mathrm{S}$ genotypes $(\beta=0.657(\mathrm{SE} \beta=0.254, N=107) v s \mathrm{Lg} / \mathrm{Lg}, \mathrm{Lg} / \mathrm{S}$, or S/S (ie, $\left.\mathrm{S}^{\prime} / \mathrm{S}^{\prime}\right)$ genotypes $(\beta=1.44(\mathrm{SE} \beta=0.340), N=36)$ fell short of statistical significance $(t=-1.629, \mathrm{df}=141$, $p=0.106)$.

\section{AS Physical Concerns}

In light of observations that only the physical concerns subscale of the ASI (ie, the fear of physical sensations such as shortness of breath and tachycardia) is known to be heritable (Stein et al, 1999), we repeated these analyses (Basic Model) exclusively for this particular component of AS. The results were comparable, but somewhat more robust. Specifically, the interaction term for the diallelic 5HTTLPR classification and level of emotional abuse was statistically significant: $\beta=0.549, \mathrm{SE} \beta=0.222, t=2.47$, $p=0.015$. When stratified by genotype (Figure 2 ), the mean $\beta$ weight for the S/S genotype $(\beta=1.126$, SE $\beta=0.237$, $N=30$ ) was once again significantly larger than the $\beta$ weight of the L/L or L/S genotypes grouped together $(\beta=0.268$, SE $\beta=0.172, N=120 ; t=-2.44, \mathrm{df}=148, p=0.016)$. Using the triallelic classification, nearly identical results were obtained: the interaction term for the 5-HTTLPR classification and level of emotional abuse was statistically significant: $\beta=0.565$, SE $\beta=0.214, t=2.64, p=0.009$. When stratified by genotype, the mean $\beta$ weights for the $\mathrm{Lg} / \mathrm{Lg}, \mathrm{Lg} / \mathrm{S}$, or S/S genotypes $(\beta=0.981$, SE $\beta=0.201, N=36$ ) was statistically significantly larger than that of the $\mathrm{La} / \mathrm{La}, \mathrm{La} / \mathrm{Lg}$, or $\mathrm{La} / \mathrm{S}$ combined group $(\beta=0.223$, SE $\beta=0.182, \quad N=107$; $t=-2.26, \mathrm{df}=141, p=0.025)$. No significant $\mathrm{G} \times \mathrm{E}$ interactions were found for the other two subscales-psychological or social concerns - of the AS (data not shown).

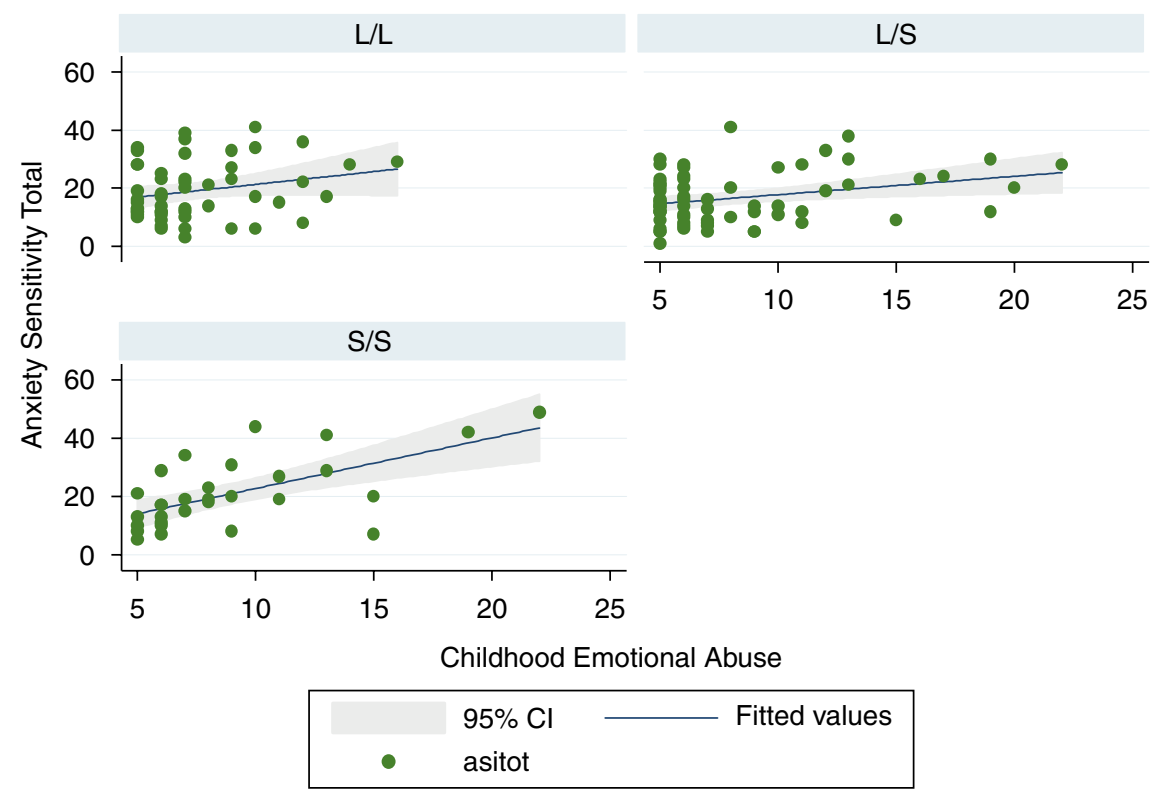

Graphs by 5 HTTLPR Diallelic

Figure I Robust linear regression analysis of childhood emotional abuse (CTQ-EA; $x$-axis) on anxiety sensitivity level (ASI total score; $y$-axis) stratified by diallelic 5-HTTLPR genotype. The slope of $S / S$ is significantly $(p=0.030)$ higher than that of $L / L$ or $L / S$ subjects combined. Y-axis is ASI total score. $X$-axis is Childhood Trauma Questionnaire Emotional Abuse score. 


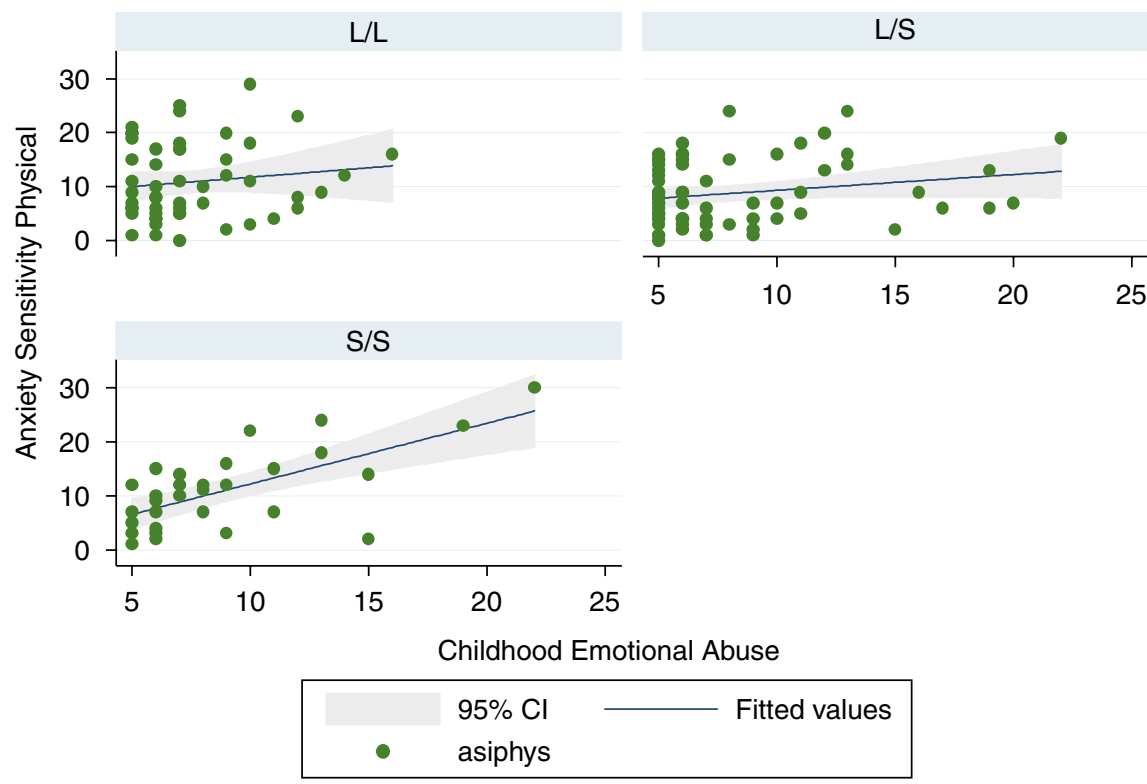

Graphs by 5 HTTLPR Diallelic

Figure 2 Robust linear regression analysis of childhood emotional abuse (CTQ-EA; $x$-axis) on anxiety sensitivity physical concerns subscale scores (ASI Physical Subscale; $y$-axis) stratified by diallelic 5-HTTLPR genotype. The slope of S/S is significantly $(p=0.0 / 6)$ higher than that of L/L or L/S subjects combined. Y-axis is ASI Physical Symptoms Subscale score. X-axis is Childhood Trauma Questionnaire Emotional Abuse score.

\section{Multivariate Models}

A series of multivariate regression models, incorporating additional covariates (Model 1: sex; Model 2: sex and ancestral proportion scores; Model 3: sex and ancestral proportion scores and neuroticism), were evaluated in the larger, ethnically diverse sample $(N=247)$. A summary of the $\beta$ weights (and their standard errors) for the interaction term (diallelic 5-HTTLPR genotype * CTQ-EA level) in each of these models is shown in Table 2. The interaction term was statistically significant in each of these models, with Model 2, which included the ancestral proportion scores, yielding larger $\beta$ weights than when not so adjusted (Model $1)$. Results were entirely consistent when confined to the European-American (EA) subsample (Table 2). In all models, S/S subjects had significantly higher AS at a given level of CTQ-EA than either L homozygotes or heterozygotes. Nearly identical results were obtained for the triallelic classification (data for Model 3 shown).

\section{Specificity of Maltreatment Type as the Stressor}

When the models in Table 2 were rerun using physical abuse (CTQ-PA) scores rather than emotional abuse (CTQEA) scores, very similar results were found for the interaction term of CTQ-PA ${ }^{\star} 5$-HTTLPR (Model 1 : $\beta=0.632$, SE $\beta=0.269, p=0.020$; Model $2: \beta=0.745$, SE $\beta=0.274, \quad p=0.007$; Model 3: $\beta=0.404$, SE $\beta=0.243$, $p=0.097)$ with AS as the outcome.

\section{Specificity of AS as the Outcome}

All multivariate models were applied to Neuroticism as the dependent variable, rather than AS. None of these models yielded a statistically significant effect for the $\mathrm{G} \times \mathrm{E}$
Table 2 Parameter Estimates for Interaction Term (5-HTTLPR*CTQ-EA) from Robust Multivariate Linear Regression Analyses Predicting ASI Total Scores

\begin{tabular}{|c|c|c|c|}
\hline & $\beta$ & SE $\beta$ & $p$-value \\
\hline \multicolumn{4}{|l|}{ Diallelic classification } \\
\hline \multicolumn{4}{|l|}{ Any ethnicity } \\
\hline Model I ${ }^{\mathrm{a}}(\mathrm{N}=247)$ & 0.533 & 0.211 & 0.012 \\
\hline Model $2^{b}(N=247)$ & 0.655 & 0.209 & 0.002 \\
\hline Model $3^{c}(N=247)$ & 0.713 & 0.187 & 0.0005 \\
\hline Model $3(N=247)^{d}$ & 0.676 & 0.193 & 0.001 \\
\hline \multicolumn{4}{|l|}{ European-American only } \\
\hline Model I $(N=150 \mathrm{EA})$ & 0.644 & 0.310 & 0.039 \\
\hline Model $2(N=150 \mathrm{EA})$ & 0.634 & 0.311 & 0.043 \\
\hline Model $3(N=150 \mathrm{EA})$ & 0.697 & 0.275 & 0.012 \\
\hline Model $3(\mathrm{~N}=150 \mathrm{EA})^{\mathrm{d}}$ & 0.753 & 0.265 & 0.005 \\
\hline
\end{tabular}

aModel I: covariates: sex.

bModel 2: covariates: sex, ancestral proportion coefficients (2).

'Model 3: covariates: sex, ancestral proportion coefficients (2), neuroticism.

${ }^{\mathrm{d}}$ Triallelic classification.

All models included 5-HTTLPR, CTQ-EA, and the interaction term (shown).

interaction between 5-HTTLPR genotype (diallelic or triallelic) and level of childhood maltreatment (EA or PA).

\section{DISCUSSION}

Anxiety sensitivity is an extremely well-replicated risk factor for anxiety (and depressive) psychopathology. The present results provide evidence for modification by severity of childhood abuse of a specific genetic influence on AS - which may be considered an intermediate pheno- 
type for anxiety and depressive disorders (Schmidt et al, 2006). These observations, along the lines of those finding effect modification by 5-HTTLPR of various forms of stress, may be yet another example of genetic influences that 'control sensitivity to the pathogenic effects of the environment' (Kendler, 2005). In terms of the particular type(s) of stress that may be relevant to the development of AS, a focus on early childhood environment - and psychosocial moderators thereof (Kaufman et al, 2004, 2006b) - may be crucial for identifying gene-by-environment interactions that influence risk for later psychopathology.

It is noteworthy that only the physical concerns component of AS - the only component known to be heritable (Stein et al, 1999) - appeared subject to this geneby-environment interaction. The possibility that fear of physical sensations is moderated by this conjoint effect of 5-HTTLPR and early emotional maltreatment suggests a possible effect on interoception as a mechanism for increased anxiety vulnerability. As noted in a recent review of brain mechanisms involved in proneness to anxiety, pathological interoceptive processing points to involvement of the insular cortex (Paulus and Stein, 2006). We have shown that individuals prone to anxiety do, indeed, have increased involvement of the insular cortex during the processing of emotional information (Stein et al, 2007). Findings from the present study should now enable the testing of specific hypotheses about gene-environment interactions and anxiety- and depressive-related endophenotypes. Several studies have documented an effect of 5HTTLPR on amygdala function during the processing of emotional faces as measured with BOLD fMRI (Hariri et al, 2005, 2006). Based on these results, we would expect, for example, that 5-HTTLPR would modify the effects of childhood emotional abuse on amygdala (and, perhaps, insular cortical) function.

This study has several limitations. First, the sample is relatively small. As a result, the number of subjects with the $\mathrm{S} / \mathrm{S}$ (or $\mathrm{S}^{\prime} / \mathrm{S}^{\prime}$ ) genotype, which drives the main findings, is also small. A robust regression package (included in STATA) was used to limit the influence of outliers, and multivariate analyses that upheld-indeed strengthened - the main findings lend additional credence to their veracity, but replication is needed. Second, although the sample is drawn from an undergraduate college student sample, it is not population-based, raising questions about generalizability; once again, replication in larger, more diverse samples is needed. Lacking psychiatric diagnostic information about the sample, we also cannot comment with confidence that the findings relate to AS as an intermediate phenotype, as opposed to the possibility that many of the subjects have DSM disorders that AS is merely tracking. Third, the assessment of maltreatment in childhood was retrospective, and assessed cross-sectionally at the same time as anxiety sensitivity levels. This limitation is mitigated somewhat by the fact that subjects were young and within a relatively narrow age range, that is, not too far temporally from the time they were asked to recall. These methodological constraints nonetheless may raise problems related to biased recall, as well as mutual heritability of both sets of factors (ie, levels of emotional abuse and anxiety sensitivity) (Moffitt et al, 2005). Consistency with 5HTTLPR findings in depression is encouraging and suggests our observations are not spurious. Nonetheless, replication in additional (ideally, longitudinal) data sets will be needed to confirm them.

Among the questions raised by our findings is the issue of specificity for particular forms of psychopathology. In a recent study replicating the gene-by-environment interaction between 5-HTTLPR and stressful life events on liability for episodes of major depression, investigators noted specificity of effects wherein they did not see this interaction increasing liability for generalized anxiety disorder (GAD) (Kendler et al, 2005). As reviewed earlier in this paper, AS is a risk factor for more than panic attacks; it is thought to increase susceptibility to a range of anxietyand depressive disorders. Keeping in mind that DSM-IV categories only imperfectly reflect the nature of psychopathology, it should be expected that genetic and experiential risk factors may at times cross diagnostic borders. Other investigators have recently commented on the likelihood that the 5-HTTLPR interaction with life stress to increase depressive symptoms reflects an impact on more proximate psychological processes, rather than on any psychiatric diagnostic entity, per se (Jacobs et al, 2006). To the best of our knowledge, this is the first report of a gene-by-environment interaction that is associated with increased levels of a trait (ie, AS) that serves as a broad susceptibility factor ('intermediate phenotype') for anxietydepressive psychopathology. Importantly, in this data set, there was some specificity for AS, as similar findings were not detected for another related trait, Neuroticism- although we must consider the possibility that this failure to find an association with neuroticism is a false negative, owing to sample size or the particular measure of neuroticism used in this study (Sen et al, 2004). On the other hand, specificity for emotional abuse was not confirmed, as similar (although somewhat less consistent) effects were seen for physical abuse, suggesting that this pathway may not discriminate between different types of stressors.

The SLC6A4 VNTR, 5-HTTLPR, is one of the best-studied genetic polymorphisms in psychiatry, and its status as a functional variant is well supported in the literature, both directly (through functional studies) and indirectly (through observed effects on phenotype). The description of an SNP variant in the VNTR region that also alters function was therefore of great interest ( $\mathrm{Hu}$ et al, 2005; Parsey et al, 2006). Specifically, the ' $\mathrm{g}$ ' SNP allele on the background of the VNTR L allele is functionally similar to the VNTR S allele-that is, this additional genotyping allows reclassification of some $\mathrm{L}$ alleles that function like $\mathrm{S}$ alleles. Making this reclassification in genetic association studies should increase power by reducing the 'noise' introduced by the presence of $\mathrm{L}$ alleles that are functionally equivalent to $S$ alleles. In our sample, this resulted in the reclassification of $16 \mathrm{~L}$ alleles as $\mathrm{S}^{\prime}$ alleles and, in the case of the heritable physical sensitivity component of AS, slightly improved statistical significance for the relevant comparison, although it did not differ substantively from the original diallelic 'L/S' classification. We should also point out that, contrary to some other studies which find that presence of one or more $S$ alleles seems to confer increased stress-related vulnerability (with no dose-response relationship for number of $S$ alleles), our findings centered on the 
impact of S homozygosity. Thus, although a very consistent literature is emerging with regard to a role for SLC6A4 and stress-related psychopathology, the precise identification of the risk-conferring variant(s) remains to be determined.

This report adds to the growing literature documenting specific examples of gene-by-environment interaction involving the 5-HTTLPR variant at the SLC6A4 locus; we now add AS to previously studied phenotypes that already include depression and alcohol use (Kaufman et al, 2006a). These results are surprising in their consistency (although, as noted above, some studies have not been consistent), and together, they suggest that this one variant plays a very substantive role in modulating an individual's stress sensitivity or resilience. We hypothesize that this variant regulates some aspect of brain function very relevant for buffering stress, which could be through a very complex mechanism, but which could also involve such theoretically quantifiable aspects of brain function as available pools of serotonin. Testing this hypothesis, and identifying other mechanisms by which constitutional variations in brain serotonin function can influence emotional resiliency to stress, are challenges for the future as we work to identify endophenotypes for stress-related psychopathology.

\section{ACKNOWLEDGEMENTS}

This study was supported in part by NIMH grant MH64122 to MBS and NIAAA grants AA11330, and NIDA grants DA12690, DA12849, and DA15105 to JG; and the US Department of Veterans Affairs (the VA Medical Research Program [Merit Review] to JG). We are grateful to Shadha Cissell and Carla Hitchcock for coordinating the study, to Alexis Rochlin for managing the database, and to Ann Marie Lacobelle and Greg Kay for excellent technical assistance.

\section{DISCLOSURE/CONFLICT OF INTEREST}

There are no conflicts for any of the authors relating to this submission.

Dr Stein reports that he has received compensation for professional services in the previous 3 years from the following entities: University of California San Diego, Veterans Affairs Healthcare System (VA), National Institutes of Health, Forest Pharmaceuticals, GlaxoSmithKline, Wyeth, Avera Pharmaceuticals, AstraZenaca, Cephalon, Pfizer, Johnson \& Johnson, Bristol-Myers Squibb, Integral Health Decisions Inc., JDS Pharmaceuticals, Solvay, Lilly, Hoffmann-La Roche, UCB Pharma, Jazz Pharmaceuticals, Comprehensive NeuroScience, Inc., and various legal firms for expert witness testimony and/or consulting.

Dr Gelernter reports that he has received compensation for professional services in the previous 3 years from the following entities: Yale University School of Medicine, Veterans Affairs Healthcare System (VA) and the National Institutes of Health (NIAAA, NIDA, and NIMH).

Dr Schork reports that he has received compensation for professional services in the previous 3 years from the following entities: University of California San Diego, National Institutes of Health, DermTech International, Ligand Pharmaceuticals, First Genetic Trust, Celera Diagnostics, Galileo Genomics, and Merck.

\section{REFERENCES}

Battaglia M, Ogliari A, Harris J, Spatola CA, Pesenti-Gritti P, Reichborn-Kjennerud T et al (2007). A genetic study of the acute anxious response to carbon dioxide stimulation in man. $J$ Psychiatr Res [E-pub ahead of print].

Bernstein A, Zvolensky MJ, Feldner MT, Lewis SF, Fauber AL, Leen-Feldner EW et al (2005). Anxiety sensitivity taxon and trauma: discriminant associations for posttraumatic stress and panic symptomatology among young adults. Depress Anxiety 22: 138-149.

Bernstein A, Zvolensky MJ, Kotov R, Arrindell WA, Taylor S, Sandin B et al (2006). Taxonicity of anxiety sensitivity: a multinational analysis. J Anxiety Disord 20: 1-22.

Bernstein DP, Fink L, Handelsman L, Lovejoy M, Wenzel K, Sapareto E et al (1994). Initial reliability and validity of a new retrospective measure of child abuse and neglect. Am J Psychiatry 151: 1132-1136.

Biederman J, Hirshfeld-Becker DR, Rosenbaum JF, Hérot C, Friedman D, Snidman N et al (2001). Further evidence of association between behavioral inhibition and social anxiety in children. Am J Psychiatry 158: 1673-1679.

Campbell CD, Ogburn EL, Lunetta KL, Lyon HN, Freedman ML, Groop LC et al (2005). Demonstrating stratification in a European American population. Nat Genet 37: 868-872.

Caspi A, Sugden K, Moffitt TE, Taylor A, Craig IW, Harrington $\mathrm{H}$ et al (2003). Influence of life stress on depression: moderation by a polymorphism in the 5-HTT gene. Science 301: 386-389.

Costa Jr PT, McCrae RR (1992). NEO PI-R Professional Manual. Psychological Assessment Resources, Inc., Odessa, FL.

Cox BJ, Borger SC, Taylor S, Fuentes K, Ross LM (1999a). Anxiety sensitivity and the five-factor model of personality. Behav Res Ther 37: 633-641.

Cox BJ, Taylor S, Enns MW (1999b). Fear of cognitive dyscontrol in relation to depression symptoms: comparisons between original and alternative measures of anxiety sensitivity. $J$ Behav Ther Exp Psychiatry 30: 301-311.

Eley TC, Sugden K, Corsico A, Gregory AM, Sham P, McGuffin P et al (2004). Gene-environment interaction analysis of serotonin system markers with adolescent depression. Mol Psychiatry 9: 908-915.

Falush D, Stephens M, Pritchard JK (2003). Inference of population structure using multilocus genotype data: linked loci and correlated allele frequencies. Genetics 164: 1567-1587.

Fox NA, Nichols KE, Henderson HA, Rubin K, Schmidt L, Hamer $\mathrm{D}$ et al (2005). Evidence for a gene-environment interaction in predicting behavioral inhibition in middle childhood. Psychol Sci 16: 921-926.

Freedman ML, Reich D, Penney KL, McDonald GJ, Mignault AA, Patterson $\mathrm{N}$ et al (2004). Assessing the impact of population stratification on genetic association studies. Nat Genet 36: 388-393.

Gelernter J, Kranzler H, Cubells JF (1997). Serotonin transporter protein (SLC6A4) allele and haplotype frequencies and linkage disequilibria in African- and European-American and Japanese populations and in alcohol-dependent subjects. Hum Genet 101: 243-246.

Gillespie NA, Whitfield JB, Williams B, Heath AC, Martin NG (2005). The relationship between stressful life events, the serotonin transporter (5-HTTLPR) genotype and major depression. Psychol Med 35: 101-111.

Grabe HJ, Lange M, Wolff B, Volzke H, Lucht M, Freyberger HJ et al (2005). Mental and physical distress is modulated by a polymorphism in the 5-HT transporter gene interacting with social stressors and chronic disease burden. Mol Psychiatry 10: 220-224.

Hariri AR, Drabant EM, Munoz KE, Kolachana BS, Mattay VS, Egan MF et al (2005). A susceptibility gene for affective disorders and the response of the human amygdala. Arch Gen Psychiatry 62: $146-152$. 
Hariri AR, Drabant EM, Weinberger DR (2006). Imaging genetics: perspectives from studies of genetically driven variation in serotonin function and corticolimbic affective processing. Biol Psychiatry 59: 888-897.

Hayward C, Killen JD, Kraemer HC, Taylor CB (2000). Predictors of panic attacks in adolescents. J Am Acad Child Adolescent Psychiatry 39: 207-214.

Hu X, Oroszi G, Chun J, Smith TL, Goldman D, Schuckit MA (2005). An expanded evaluation of the relationship of four alleles to the level of response to alcohol and the alcoholism risk. Alcohol Clin Exp Res 29: 8-16.

Jacobs N, Kenis G, Peeters F, Derom C, Vlietinck R, van Os J (2006). Stress-related negative affectivity and genetically altered serotonin transporter function: evidence of synergism in shaping risk of depression. Arch Gen Psychiatry 63: 989-996.

Kaufman J, Yang BZ, Douglas-Palumberi H, Crouse-Artus M, Lipschitz D, Krystal JH et al (2006a). Genetic and environmental predictors of early alcohol use. Biol Psychiatry [E-pub ahead of print].

Kaufman J, Yang BZ, Douglas-Palumberi H, Grasso D, Lipschitz D, Houshyar S et al (2006b). Brain-derived neurotrophic factor5 -HTTLPR gene interactions and environmental modifiers of depression in children. Biol Psychiatry 59: 673-680.

Kaufman J, Yang BZ, Douglas-Palumberi H, Houshyar S, Lipschitz $\mathrm{D}$, Krystal JH et al (2004). Social supports and serotonin transporter gene moderate depression in maltreated children. Proc Natl Acad Sci USA 101: 17316-17321.

Kendler KS (2005). 'A gene for...': the nature of gene action in psychiatric disorders. Am J Psychiatry 162: 1243-1252.

Kendler KS, Kuhn JW, Vittum J, Prescott CA, Riley B (2005). The interaction of stressful life events and a serotonin transporter polymorphism in the prediction of episodes of major depression: a replication. Arch Gen Psychiatry 62: 529-535.

Lang AJ, Kennedy CM, Stein MB (2002). Anxiety sensitivity and PTSD among female victims of intimate partner violence. Depress Anxiety 16: 77-83.

Lesch K-P, Bengel D, Heils A, Sabol SA, Greenberg BD, Petri S et al (1996). Association of anxiety-related traits with a polymorphism in the serotonin transporter gene regulatory region. Science 274: $1527-1531$.

Middeldorp CM, Cath DC, Van Dyck R, Boomsma DI (2005). The co-morbidity of anxiety and depression in the perspective of genetic epidemiology. A review of twin and family studies. Psychol Med 35: 611-624.

Moffitt TE, Caspi A, Rutter M (2005). Strategy for investigating interactions between measured genes and measured environments. Arch Gen Psychiatry 62: 473-481.

Parsey RV, Hastings RS, Oquendo MA, Hu X, Goldman D, Huang YY et al (2006). Effect of a triallelic functional polymorphism of the serotonin-transporter-linked promoter region on expression of serotonin transporter in the human brain. Am J Psychiatry 163: $48-51$.

Paulus MP, Stein MB (2006). An insular view of anxiety. Biol Psychiatry 60: 383-387.

Peterson RA, Reiss S (1992). Anxiety Sensitivity Index manual, 2nd edn. International Diagnostic Systems: Worthington, $\mathrm{OH}$.

Pritchard JK, Rosenberg NA (1999). Use of unlinked genetic markers to detect population stratification in association studies. Am J Hum Genet 65: 220-228.

Pritchard JK, Stephens M, Rosenberg NA, Donnely P (2000). Association mapping in structured populations. Am J Hum Genet 67: 170-181.

Reiss S (1991). Expectancy theory of fear, anxiety, and panic. Psychol Rev 11: 141-153.

Scher CD, Forde DR, McQuaid JR, Stein MB (2004). Prevalence and demographic correlates of childhood maltreatment in an adult community sample. Child Abuse Neglect 28: 167-180.

Scher CD, Stein MB (2003). Developmental antecedents of anxiety sensitivity. J Anxiety Disord 17: 253-269.
Scher CD, Stein MB, Asmundson GJ, McCreary DR, Forde DR (2001). The childhood trauma questionnaire in a community sample: psychometric properties and normative data. J Traum Stress 14: 843-857.

Schmidt NB, Lerew DR, Jackson RJ (1997). The role of anxiety sensitivity in the pathogenesis of panic: prospective evaluation of spontaneous panic attacks during acute stress. J Abnorm Psychol 106: 355-364.

Schmidt NB, Lerew DR, Jackson RJ (1999). Prospective evaluation of anxiety sensitivity in the pathogenesis of panic: replication and extension. J Abnorm Psychol 108: 532-537.

Schmidt NB, Mallott M (2006). Evaluating anxiety sensitivity and other fundamental sensitivities predicting anxiety symptoms and fearful responding to a biological challenge. Behav Res Ther 44: 1681-1688.

Schmidt NB, Zvolensky MJ, Maner JK (2006). Anxiety sensitivity: prospective prediction of panic attacks and Axis I pathology. J Psychiatric Res 40: 691-699.

Sen S, Burmeister M, Ghosh D (2004). Meta-analysis of the association between a serotonin transporter promoter polymorphism (5-HTTLPR) and anxiety-related personality traits. Am J Med Genet 127B: 85-89.

Smoller JW, Tsuang MT (1998). Panic and phobic anxiety: defining phenotypes for genetic studies. Am J Psychiatry 155: 1152-1162.

StataCorp (2003). Stata Statistical Software. [Release 9.2]. Stata Corporation: College Station, TX.

Stein MB, Jang KL, Livesley WJ (1999). Heritability of anxiety sensitivity: a twin study. Am J Psychiatry 156: 246-251.

Stein MB, Rapee RM (1998). Anxiety sensitivity: is it all in the head?. In: Taylor S (ed). Lawrence Erlbaum Associates: Mahwah, NJ, pp 199-215.

Stein MB, Seedat S, Gelernter J (2006). Serotonin transporter gene promoter polymorphism predicts SSRI response in generalized social anxiety disorder. Psychopharmacology (Berl) 187: $68-72$.

Stein MB, Simmons A, Feinstein JS, Paulus MP (2007). Increased amygdala and insula activation during emotion processing in anxiety-prone subjects. Am J Psychiatry 164: 318-327.

Surtees PG, Wainwright NW, Willis-Owen SA, Luben R, Day NE, Flint J (2006). Social adversity, the serotonin transporter (5-HTTLPR) polymorphism and major depressive disorder. Biol Psychiatry 59: 224-229.

Taylor S, Koch WJ, Woody S, McLean P (1996). Anxiety sensitivity and depression: how are they related? J Abnorm Psychol 105: 474-479.

Thombs BD, Bernstein DP, Ziegelstein RC, Scher CD, Forde DR, Walker EA et al (2006). An evaluation of screening questions for childhood abuse in 2 community samples: implications for clinical practice. Arch Intern Med 166: 2020-2026.

Wendland JR, Martin BJ, Kruse MR, Lesch KP, Murphy DL (2006). Simultaneous genotyping of four functional loci of human SLC6A4, with a reappraisal of 5-HTTLPR and rs25531. Mol Psychiatry 11: 224-226.

Wilhelm K, Mitchell PB, Niven H, Finch A, Wedgwood L, Scimone A et al (2006). Life events, first depression onset and the serotonin transporter gene. Br J Psychiatry 188: 210-215.

Yang BZ, Zhao H, Kranzler HR, Gelernter J (2005). Practical population group assignment with selected informative markers: characteristics and properties of Bayesian clustering via STRUCTURE. Genet Epidemiol 28: 302-312.

Zalsman G, Huang YY, Oquendo MA, Burke AK, Hu XZ, Brent DA et al (2006). Association of a triallelic serotonin transporter gene promoter region (5-HTTLPR) polymorphism with stressful life events and severity of depression. Am J Psychiatry 163: 1588-1593.

Zinbarg RE, Brown TA, Barlow DH, Rapee RM (2001). Anxiety sensitivity, panic, and depressed mood: a reanalysis teasing apart the contributions of the two levels in the hierarchical structure of the Anxiety Sensitivity Index. J Abnorm Psychol 110: 372-377. 